\title{
NEW METHOD FOR THE SIMULTANEOUS ESTIMATION OF SIPONIMOD AND PONESIMOD \\ BY USING ULTRA PERFORMANCE LIQUID CHROMATOGRAPHIC SYSTEM IN ACTIVE PHARMACEUTICAL INGREDIENT FORM
}

\author{
Anita. Kethipalli ${ }^{1}$, Dittakavi. Ramachandran*2 \\ 1,2 Department of Chemistry, Acharya Nagarjuna University, Guntur, India. \\ *Corresponding author: ramchandran.anu22@gmail.com
}

\begin{abstract}
The aim of this study is to create and validate a fast, easy-to-use, affordable, sensitive, and accurate method for measuring Siponimod and Ponesimod in bulk and pharmaceutical products using Reversed-Phase Ultra-Performance Liquid Chromatography (RP-UPLC). A Luna C18 column was used with a running phase composed of $0.1 \%$ trifluoroacetic acid: acetonitrile $(30: 70 \mathrm{v} / \mathrm{v})$ at a flow rate of 1.0 $\mathrm{ml} / \mathrm{min}$. UV detection was used at a wavelength of $230 \mathrm{~nm}$. Ponesimod and Siponimod correlation coefficients were found to be 0.999 over a concentration range of $5-75 \mu \mathrm{g} / \mathrm{ml}$ and $0.5-7.5 \mu \mathrm{g} / \mathrm{ml}$, respectively. Ponesimod and Siponimod have respective retention times of 1.751 and 3.203 minutes. The run time for separating Ponesimod and Siponimod peaks was 5 minutes. The validation results agreed with what's acceptable and had good limits. This method, proposed as a regular analysis and quality control tool for medications that contain these active drugs either individually or in combination, was evident to be a suitable one.
\end{abstract}

Keywords: UPLC, Ponesimod, Siponimod, Development, Validation.

\section{Introduction}

Ponvory, also known as Ponesimod, is a drug used to treat multiple sclerosis (MS) ${ }^{[1-2]}$. Upper respiratory tract infection ${ }^{[3-4]}$, hepatic transaminase elevation ${ }^{[5-6], ~ a n d ~}$ hypertension ${ }^{[7]}$ are the most common side effects. Temporary bradycardia ${ }^{[8]}$ dyspnea] ${ }^{[9-10]}$ and elevated liver enzymes ${ }^{[11-12]}$ are all frequent side effects, often noticed in the early stages of treatment (without symptoms). There was no observable increase in infections after ponesimod treatment. A study has discovered that QT prolongation is present, but it was insignificant enough to be of clinical importance ${ }^{[13]}$. The sphingosine1-phosphate receptor ${ }^{[14-15]}$ blocker ponesimod, which is already used for the treatment of MS, functions in a similar way to fingolimod. The lymphocyte ${ }^{[16]}$ escape mechanism makes sure that lymphocytes (a type of white blood cell) stay in lymph nodes. Ponesimod prefers S1P1, which is one of the subtypes of this receptor. The European Medicines Agency's Committee for Medicinal Products for Human Use (CHMP) adopted a positive 
opinion on Ponvory, a medicine for the treatment of multiple sclerosis, and recommended granting it a marketing authorization.

A brand-name drug called Mayzent that is used for multiple sclerosis (MS) is a selective sphingosine-1-phosphate receptor modulator (S1P-R modulator) ${ }^{[17-18]}$ for oral administration. Siponimod is used to treat secondary progressive multiple sclerosis (SPMS), a chronic, worsening disease in which multiple sclerosis (MS) symptoms progress without the occurrence of acute relapses. In the case of active SPMS, siponimod helps prevent disability and the risk of further MS relapses. Most patients exhibited symptoms such as headaches ${ }^{[19-20]}$ elevated blood pressure ${ }^{[21]}$ and liver abnormalities. In Figure 1 chemical representation of Ponesimod and Siponimod were shown.

Simultaneous determination of Siponimod and Ponesimod using UPLC was found in the current study. HPLC separation and analysis times are slower than UPLC because it allows better separation. To separate Siponimod and Ponesimod, we used UPLC.

Till now, there have no UPLC and HPLC reports available for the estimation of Ponesimod and only one report available for Siponimod ${ }^{[22]}$ There were no methods available in combination. Hence, we employed UPLC method to determine both drugs.

\section{Experimental Study}

\section{Solutions and Reagents}

The pure Ponesimod and Siponimod used in this study was provided by Glenmark Pharmaceutical Private Ltd., located in Andheri (E), Mumbai, India (99.7-99.9 percent purity). Other reagents, including acetonitrile, trifluoroacetic acid, and water, were obtained from Merck (India) Ltd. in Worli, Mumbai, India, and were of HPLC grade.

\section{Collection of instruments}

Waters Acquity UPLC system with a quaternary pump and PDA detector (PDA lamp). Processing data was completed using Empower 2.0.

\section{Buffers are chosen}

An easy, inexpensive, and appropriate acidic buffer was chosen, such as 0.1 percent trifluoroacetic acid (Observed $\mathrm{pH}-2.3)$.

\section{Step of mobility}

For Standard review, the mobile step was 0.1\% TFA buffer in a 30:70 (v/v) acetonitrile mixture and was degassed beforehand. A mobile phase chosen to produce well-defined peaks with a low tailing factor (2.0) and a plate count of over 2000 was selected.

\section{Prepare the diluent}

The diluent's mobile process was set up. 


\section{Conditions of Chromatography}

For the UPLC experiments, a Luna C18 $(100 \times 2.6 \mathrm{~mm}, 1.6 \mu \mathrm{m})$ was used. The elution was conducted with isocratic conditions using acetonitrile: TFA ( $0.1 \%$ volume) (70:30 by volume) at a flow rate of $1.0 \mathrm{ml} / \mathrm{min}$. The injection volume was $10 \mu 1$, and the run time was 5 minutes, with the column temperature set to room temperature and the absorbance measured at $230 \mathrm{~nm}$ (Because maximum absorbance was observed at this wavelength. So, this was selected as wavelength).

\section{Standard Solution Preparation}

To dilute $50 \mathrm{mg}$ of Ponesimod and $5 \mathrm{mg}$ of Siponimod, measure out the drug and transfer it to a $100 \mathrm{~mL}$ volumetric flask, then add approximately $70 \mathrm{~mL}$ of a diluent and sonicate for 30 minutes to melt it, after which you must add more diluent to the total amount. Dilute the solution in the original recipe to $50 \mathrm{~mL}$ with diluents.

\section{Validation Process}

\section{System Precision}

The system's performance has been validated through assessment of device suitability parameters. Limits were found to be met for a variety of parameters, including plate count, tailing, and RSD percentage.

\section{Specificity}

Being able to identify and test a given analyte in the presence of other elements required to be combined in the Standard and the standard solution is known as specificity. Blank Standards and those with Ponesimod and Siponimod will be tested using chromatograms.

\section{Accuracy}

Being close to the real meaning of the technique is what defines accuracy. Three concentrations will be used to test the recovery trials. The drug's quantity, percentage of recovery, and standard deviations were calculated after every injection at each level.

\section{Precision}

It is the level of agreement between the various test results that determines the precision of the analytical methodology. Researchers examined the effects of sampling a homogeneous population more than once. The current process was evaluated in terms of its ability to provide repeatable, intraday, and inter-day results. It was examined by sampling the materials on the same day and over the course of different days.

\section{Linearity}

Linearity is the feature of analytical process which allows for a direct proportion of analytical results in response to a certain concentration of the analyte in the Standard. A total of seven series of standard solutions were selected for the assessment of the linearity spectrum. The calibration curve was drawn by comparing regular solution concentration with peak area. Using the least square method, the slope, intercept, and coefficient of correlation were calculated. 


\section{Forced Degradation}

The peaks in the chromatogram should agree. ICH guidance Q1(A) R2 was performed in conjunction with stress degradation experiments. The peaks of degradation should be well distanced and at least 1.0 resolution between peaks. For the largest peaks to go over, a separation must occur. A degradation of around 20 percent has been attained via several various stress conditions ${ }^{[23]}$ like acid, alkali, peroxide, reduction, thermal and photo in what is known as a forced degradation experiment.

\section{Robustness}

Robustness refers to a procedure's resistance to small process parameter changes, as well as its reliability in normal operation. An organic solution was introduced into the UPLC system for a robustness analysis, and the chromatographic settings (such as flow rate and mobile-phase organic content) were modified. The separation factor, retention time, and peak asymmetry were determined by evaluating the effects of altered parameters.

\section{Results and Discussion}

The aim of this study is to establish a single isocratic UPLC method for the simultaneous quantification of Ponesimod and Siponimod in bulk and pharmaceutical dosage forms that is reliable, precise, and cost effective. According to the UV spectra of these compounds, an appropriate wavelength for simultaneous estimation of two drugs was chosen.

\section{Optimization of the method}

Using buffers $(0.1 \% \text { orthophosphoric acid, } 0.1 \% \text { formic acid, } 0.1 \% \text { triethylamine })^{[24]}$ and acetonitrile as mobile phase different trials were conducted in isocratic and gradient modes. Various stationary phases including phenyl, biphenyl, amino, $\mathrm{C} 4$, and $\mathrm{C} 8$, were used to test the system. The resolution and retention times were improved by changing the mobile step composition at each trial. In the end, the separation was achieved using a Luna C18 column $(100 \mathrm{~mm} \times 2.6 \mathrm{~mm}, 1.6 \mu \mathrm{m})$ and a mobile phase of $0.1 \%$ TFA: acetonitrile $(30: 70 \mathrm{v} / \mathrm{v})$ with a flow rate of $1.0 \mathrm{ml} / \mathrm{min}$ and $\mathrm{UV}$ detection at a wavelength of $230 \mathrm{~nm}$. The entire performance lasted five minutes. Conditions for optimized chromatography are provided in table 1 .

\section{System Suitability}

To attain results, the following device suitability parameters were established after six consecutive injections of normal solution: theoretical plate number, time, peak area, tailing factor, and resolution. The chromatogram in Figure 2 was the representative of the suitability results detailed in table 2 . 
Table 1. Method suitability conditions

\begin{tabular}{|c|c|}
\hline Parameter & Suitable conditions \\
\hline Column & Luna $\mathrm{C}_{18}(100 \times 2.6 \mathrm{~mm}, 2.6 \mu)$ \\
\hline Moving Phase & $0.1 \%$ Tri fluoro acetic acid: Acetonitrile $(30: 70 \mathrm{v} / \mathrm{v})$ \\
\hline Volume of injection & $10 \mu 1$ \\
\hline Stream rate & $1.0 \mathrm{~mL} / \mathrm{min}$ \\
\hline Temperature of column & $25^{\circ} \mathrm{C}$ \\
\hline Wavelength & $230 \mathrm{~nm}$ \\
\hline Time duration & $5 \mathrm{minutes}$ \\
\hline Retention time of Ponesimod & $1.754 \mathrm{~min}$ \\
\hline Retention time of Siponimod & $3.206 \mathrm{~min}$ \\
\hline
\end{tabular}

Table 2. Results of system suitability

\begin{tabular}{|c|c|c|}
\hline Parameter & Ponesimod & Siponimod \\
\hline Number of plates & 2487 & 4263 \\
\hline Tailing & 1.02 & 1.05 \\
\hline Resolution & - & 7.84 \\
\hline Peak elution time & 1.754 & 3.206 \\
\hline$\%$ RSD & 0.58 & 0.93 \\
\hline
\end{tabular}

\section{Specificity}

There was no participation from Ponesimod and Siponimod at the elution time. As seen in Figure 1, the blank chromatogram is present.

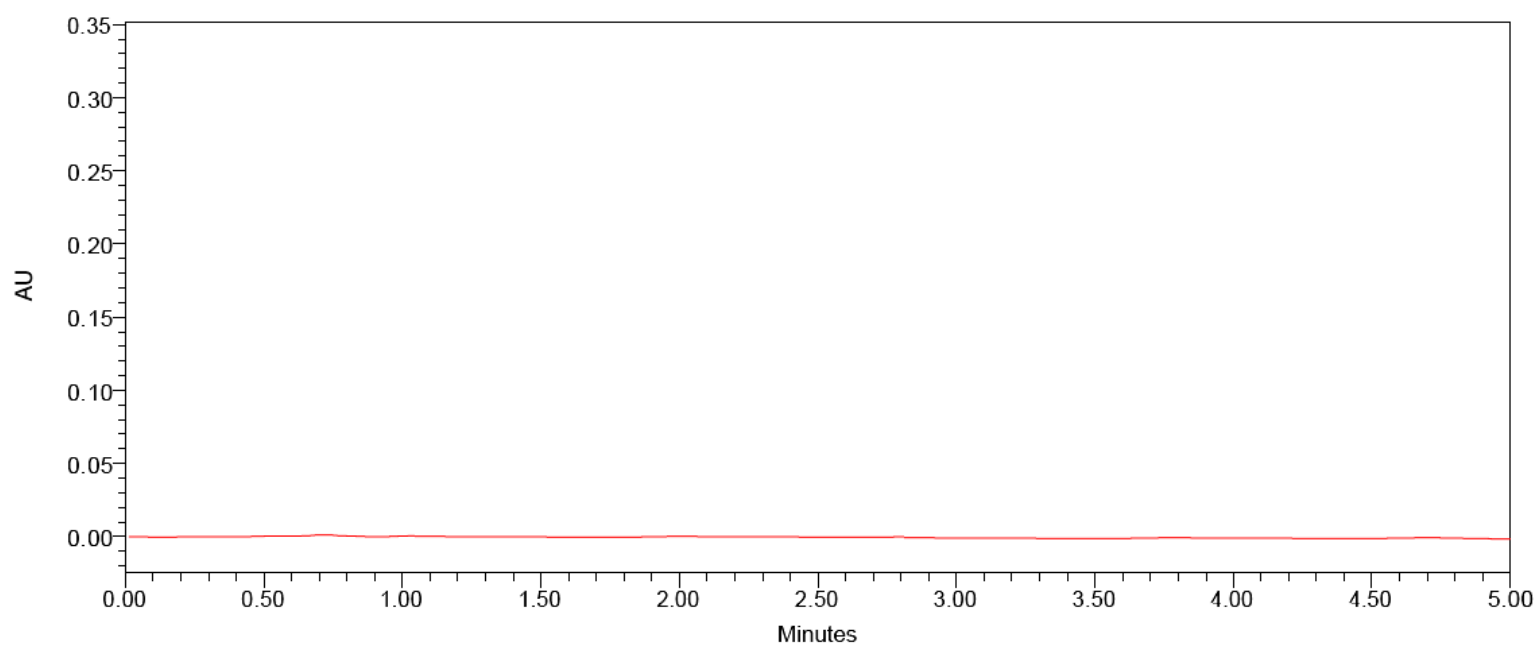

Figure 1. Chromatogram of blank 


\section{Linearity}

By using a calibration curve to determine the linearity of the area of peak, its corresponding concentration was discovered. From this graph, it appears that the range of $5-75 \mu \mathrm{g} / \mathrm{mL}$ of Ponesimod and $0.5-7.5 \mu \mathrm{g} / \mathrm{mL}$ of Siponimod had a straight line. For Ponesimod, the equations of regression were $\mathrm{Y}=43100.41 \mathrm{x}+51890.06(\mathrm{R} 2=0.9991)$ and $\mathrm{Y}=56913.45 \mathrm{x}+3363.27(\mathrm{R} 2=0.9993)$ for Siponimod, respectively. Linearity results were demonstrated in table 3 .

Table 3. Results of linearity

\begin{tabular}{|c|c|c|c|c|}
\hline \multirow{2}{*}{ S. No } & \multicolumn{2}{|c|}{ Ponesimod } & \multicolumn{2}{c|}{ Siponimod } \\
\cline { 2 - 5 } & $\begin{array}{c}\text { Concentration } \\
(\mu \mathrm{g} / \mathrm{mL})\end{array}$ & Area & $\begin{array}{c}\text { Concentration } \\
(\mu \mathrm{g} / \mathrm{mL})\end{array}$ & Area \\
\hline 1 & 5.00 & 283157 & 0.50 & 30812 \\
\hline 2 & 12.50 & 628487 & 1.25 & 77837 \\
\hline 3 & 25.00 & 1191250 & 2.50 & 152790 \\
\hline 4 & 37.50 & 1631664 & 3.75 & 216985 \\
\hline 5 & 50.00 & 2130781 & 5.00 & 281081 \\
\hline 6 & 62.50 & 2793848 & 6.25 & 352775 \\
\hline 7 & 75.00 & 3285293 & 7.50 & 437061 \\
\hline
\end{tabular}

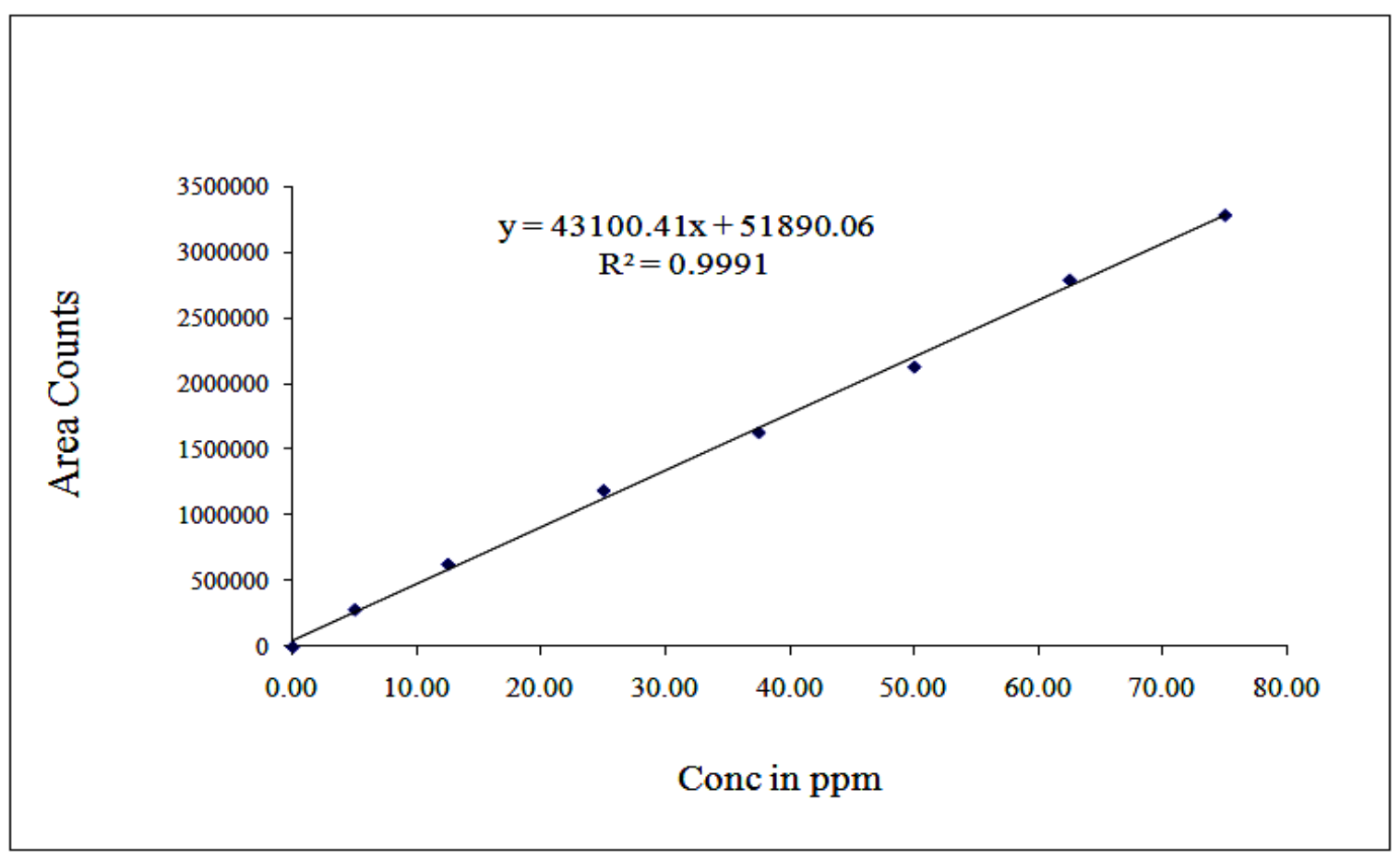

Figure 2. Calibration plot of Ponesimod 


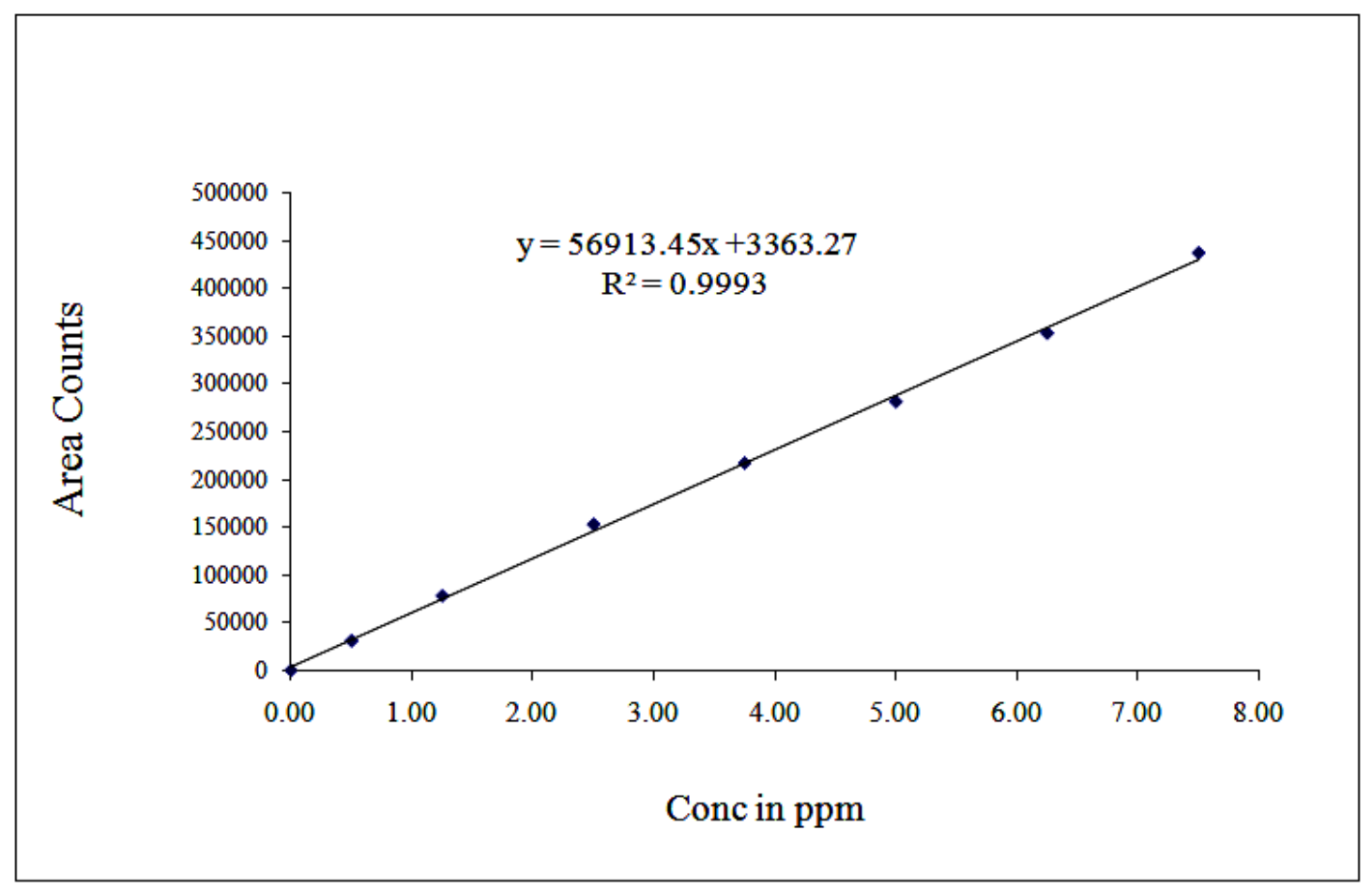

Figure 3. Calibration plot of Siponimod

\section{Precision}

Intraday and intermediate precision variances were assessed in relation to the procedure's accuracy. The Standards were examined six times on the same day to obtain intraday results for Ponesimod and Siponimod. The system's intermediate precision was explored by analyzing data in the same laboratory using a variety of examiners and tools. It is very accurate, with an RSD percentage of less than $2 \%$. The process was precise, yielding the best drug recoveries at each additional concentration. Table 4 shows the method precision results.

Table 4. Outcomes of method precision

\begin{tabular}{|c|c|c|c|c|}
\hline \multirow{2}{*}{ S. No. } & \multicolumn{2}{|c|}{ Ponesimod } & \multicolumn{2}{c|}{ Siponimod } \\
\cline { 2 - 5 } & Area & \% Assay & Area & \% Assay \\
\hline 1 & 2159715 & 99.9 & 271128 & 98.5 \\
\hline 2 & 2180789 & 100.8 & 272087 & 98.8 \\
\hline 3 & 2169223 & 100.3 & 274278 & 99.6 \\
\hline 4 & 2145136 & 99.2 & 275687 & 100.1 \\
\hline 5 & 2169054 & 100.8 & 271713 & 98.7 \\
\hline 6 & 2151732 & 99.5 & 272174 & 98.9 \\
\hline Mean & 2162608 & 100.1 & 272845 & 99.1 \\
\hline Std. dev & 13021.41 & 0.668 & 1754.12 & 0.616 \\
\hline \% RSD & 0.602 & 0.67 & 0.643 & 0.62 \\
\hline
\end{tabular}




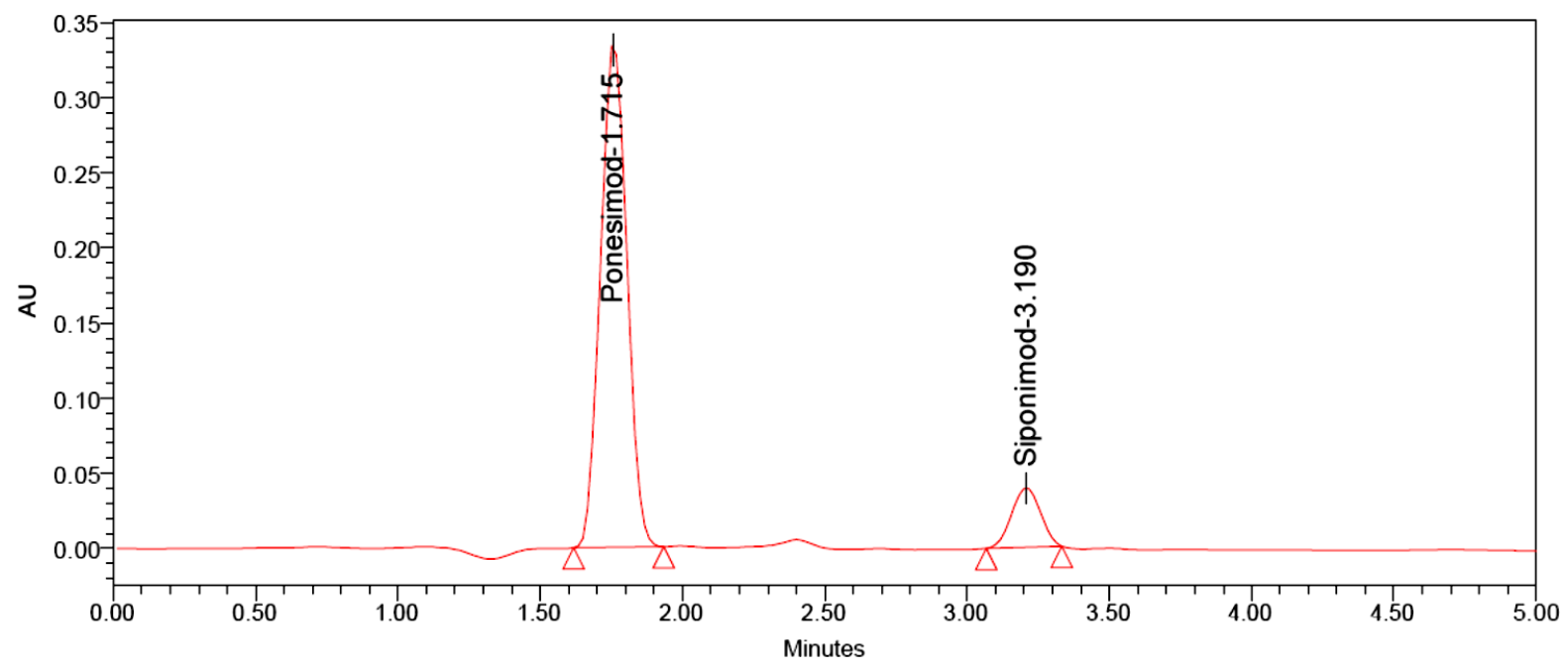

Figure 4. Chromatogram of method precision

\section{Intermediate Precision (Ruggedness)}

Intermediate precision results were shown in table 5.

Table 5. Results of intermediate precision

\begin{tabular}{|c|c|c|c|c|}
\hline \multirow{2}{*}{ S. No. } & \multicolumn{2}{|c|}{ Ponesimod } & \multicolumn{2}{c|}{ Siponimod } \\
\cline { 2 - 5 } & Area & \% Assay & Area & \% Assay \\
\hline 1 & 2162738 & 99.9 & 280178 & 101.5 \\
\hline 2 & 2175787 & 100.5 & 273295 & 99.1 \\
\hline 3 & 2166247 & 100.1 & 280248 & 101.6 \\
\hline 4 & 2149118 & 99.3 & 281218 & 101.9 \\
\hline 5 & 2159097 & 99.7 & 278245 & 100.8 \\
\hline 6 & 2156718 & 99.6 & 272254 & 98.7 \\
\hline Mean & 2161618 & 99.9 & 277573 & 100.6 \\
\hline Std dev & 9056.03 & 0.418 & 3854.15 & 1.371 \\
\hline$\%$ RSD & 0.419 & 0.42 & 1.389 & 1.36 \\
\hline
\end{tabular}

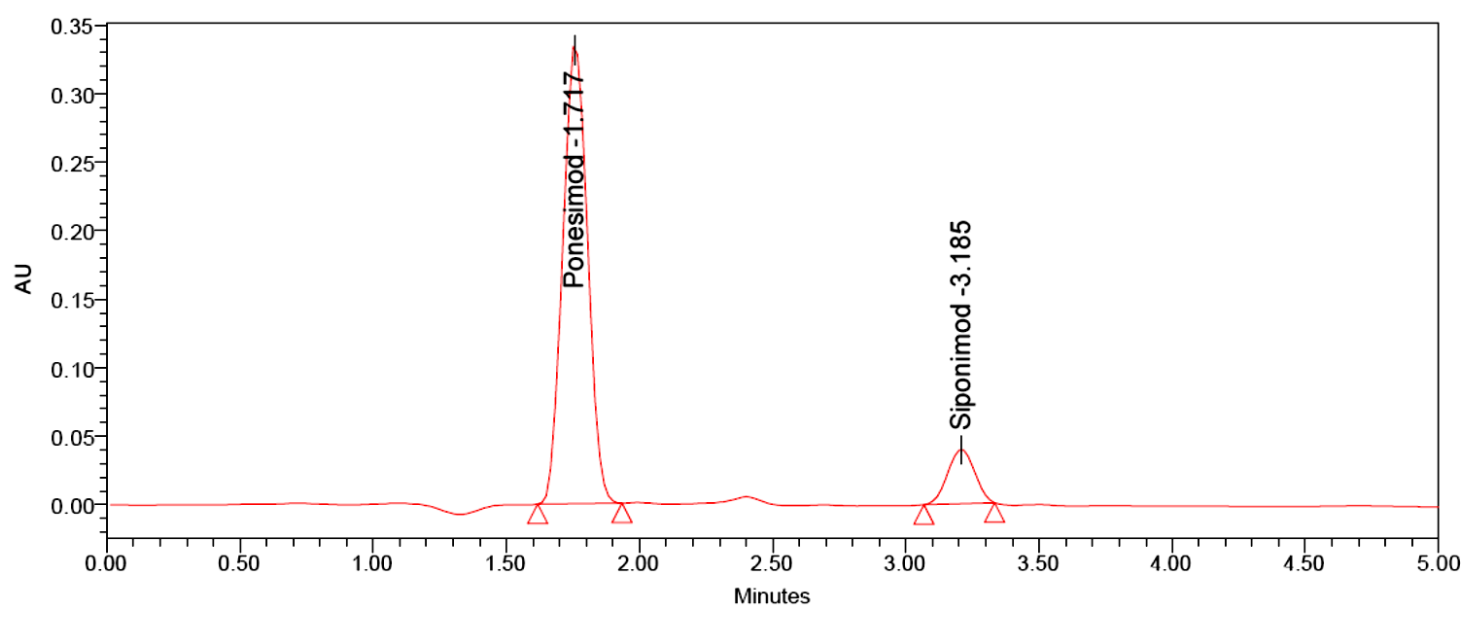

Figure 5. Chromatogram of intermediate precision 


\section{Accuracy}

By measuring the recovery experiments at three stages, the method's precision was reached (50 percent, 100 percent, and 150 percent). APIs were made with concentrations of Ponesimod of 25, 50, and 75 micrograms $/ \mathrm{mL}$ and Siponimod of 2.5, 5 and 7.5 micrograms $/ \mathrm{mL}$. For each stage of the spike, the test solution was injected three times, and the assay was performed in accordance with the test process. In addition to being able to determine the percentage of recovered data, the mean and relative standard deviations have also been found. The strategy was effective because the recovery values fell within the target range. Table 6 presents the accuracy results.

Table 6. Results of accuracy

\begin{tabular}{|c|c|c|c|c|}
\hline Accuracy & $\begin{array}{c}\text { Amount of } \\
\text { Ponesimod }\end{array}$ & $\begin{array}{c}\% \\
\text { Recovery }\end{array}$ & $\begin{array}{c}\text { Amount of } \\
\text { Siponimod }\end{array}$ & $\begin{array}{c}\% \\
\text { Recovery }\end{array}$ \\
\hline $50 *$ & 25 & 100.6 & 2.5 & 101.0 \\
\hline $100 *$ & 50 & 98.5 & 5 & 101.4 \\
\hline $150 *$ & 75 & 101.0 & 7.5 & 101.7 \\
\hline
\end{tabular}

* Results are mean recovery of three sample preparations

\section{LOD and LOQ}

The concentration level at which the analytes are reliably detected and quantified is the limit of detection and quantification. Ponesimod and Siponimod had a LOD concentrations of $1.5 \mu \mathrm{g} / \mathrm{ml}, 0.15 \mu \mathrm{g} / \mathrm{ml}$ and their $\mathrm{S} / \mathrm{N}$ values of 6,3 . The LOQ concentrations of Ponesimod and Siponimod were $5 \mu \mathrm{g} / \mathrm{ml}, 0.5 \mu \mathrm{g} / \mathrm{ml}$, and their $\mathrm{S} / \mathrm{N}$ values were 25,22 . ( $\mathrm{S} / \mathrm{N}$ is the ratio of signal to noise).

\section{Robustness}

To ensure the robustness of the chromatographic technique, the researchers evaluated flow rate and the composition of the mobile phase. By changing the flow rate and mobile phase ratio, the area of drugs changes. So, the percentage of relative standard deviation changes. Here in Table 7 (robustness results) the \%RSD values are in within the acceptable limit.

Table 7. Outcomes of robustness

\begin{tabular}{|c|c|c|}
\hline Parameter & \% RSD of Ponesimod & \% RSD of Siponimod \\
\hline Flow $(0.8 \mathrm{~mL} / \mathrm{min})$ & 0.35 & 0.42 \\
\hline Flow $(1.2 \mathrm{~mL} / \mathrm{min})$ & 0.95 & 0.87 \\
\hline Organic phase $(77: 23)$ & 0.70 & 0.86 \\
\hline Organic phase $(63: 37)$ & 0.20 & 1.25 \\
\hline
\end{tabular}




\section{Forced Degradation}

The proposed approach can be used for successful evaluations of release and stability tests, and it can be called a stability preferable technique. Acid, Alkali, oxidation, reduction, photo, and thermal degradation are all included in the ICH-required forced degradation analysis. The chromatograms show that the selected drugs remained stable under the stress conditions, despite the presence of degraded peaks. Results of forced degradation were given in table 8 and 9 , forced degradation chromatograms were shown in figure 4.

\section{Acid degradation}

A volume of $1 \mathrm{ml}$ Standard stock solution was transferred to a volumetric flask with a capacity of $10 \mathrm{ml}$, to which $1 \mathrm{ml}$ of $1 \mathrm{~N} \mathrm{HCl}$ was added and left to stand for 15 minutes. After 15 min add $1 \mathrm{ml}$ of $1 \mathrm{~N} \mathrm{NaOH}$ and make up to the diluent mark. Filter the solution using syringe filter and injected into UPLC system.

\section{Alkali degradation}

A volume of $1 \mathrm{ml}$ Standard stock solution was transferred to a volumetric flask with a capacity of $10 \mathrm{ml}, 1 \mathrm{ml}$ of $1 \mathrm{~N} \mathrm{NaOH}$ was added, and the mixture was left to stand for 15 minutes. After 15 minutes, add $1 \mathrm{~mL}$ of $1 \mathrm{~N} \mathrm{HCl}$ to bring the solution up to the required concentration. Use a syringe filter to filter the solution, which will then be injected into the UPLC system.

\section{Peroxide degradation}

A volume of $1 \mathrm{ml}$ Standard stock solution was moved to a volumetric flask of $10 \mathrm{ml}$, add $1 \mathrm{ml}$ of $30 \%$ hydrogen peroxide solution and make up to the mark with diluents. Filter the solution using syringe filter and injected into UPLC system.

\section{Reduction degradation}

Using a volumetric flask with a capacity of $10 \mathrm{ml}$, transfer $1 \mathrm{ml}$ of Standard stock solution and add $1 \mathrm{ml}$ of $30 \%$ hydrogen peroxide solution, then dilute to the required concentration with diluents. Use a syringe filter to filter the solution, which will then be injected into the UPLC system.

\section{Thermal degradation}

During the 6-hour baking period, the Standard solution was kept at $105^{\circ} \mathrm{C}$. The resulting solution was injected into an ultra-performance liquid chromatography system.

\section{Photolytic degradation}

A weight of 100mg Standard was exposed to sunlight for $6 \mathrm{hrs}$. and the exposed Standard was analyzed. Prepare the Standard solution by using this Standard and inject into UPLC system. 
Table 8. FD results of Ponesimod

\begin{tabular}{|c|c|c|c|c|c|}
\hline \multirow[b]{2}{*}{ Stress Parameter (24 hrs) } & \multicolumn{5}{|c|}{ Ponesimod } \\
\hline & $\%$ Deg & $\%$ Assay & $\begin{array}{l}\text { Purity } \\
\text { angle }\end{array}$ & $\begin{array}{c}\text { Purity } \\
\text { threshold }\end{array}$ & $\begin{array}{l}\text { Mass } \\
\text { balance }\end{array}$ \\
\hline Acid degradation $(1 \mathrm{~N} \mathrm{HCl})$ & 17.4 & 82.4 & 0.341 & 10.883 & 99.8 \\
\hline Alkali degradation $(1 \mathrm{~N} \mathrm{NaOH})$ & 16.5 & 82.8 & 0.352 & 10.867 & 99.3 \\
\hline Peroxide degradation (30\% Peroxide) & 14.3 & 85.2 & 1.157 & 10.328 & 99.5 \\
\hline $\begin{array}{l}\text { Reduction degradation (30\% sodium bi } \\
\text { sulphate) }\end{array}$ & 16.6 & 83.1 & 1.136 & 10.346 & 99.7 \\
\hline Thermal (sample, $70^{\circ} \mathrm{C}, 6 \mathrm{Hrs}$ ) & 12.1 & 87 & 0.339 & 10.839 & 99.1 \\
\hline $\begin{array}{l}\text { Photo (UV-Vis light- }\left(200 \mathrm{~W} \mathrm{~h} / \mathrm{m}^{2}\right) \\
\text { and fluorescent light }(1.2 \text { milliion lux- } \\
\mathrm{h})\end{array}$ & 13.9 & 84.5 & 0.362 & 10.868 & 98.4 \\
\hline
\end{tabular}

Table 9. FD results of Siponimod

\begin{tabular}{|c|c|c|c|c|c|}
\hline \multirow{2}{*}{ Stress Parameter (24 hrs) } & \multicolumn{5}{|c|}{ Ponesimod } \\
\cline { 2 - 6 } & $\%$ Deg & $\%$ Assay & $\begin{array}{c}\text { Purity } \\
\text { angle }\end{array}$ & $\begin{array}{c}\text { Purity } \\
\text { threshold }\end{array}$ & $\begin{array}{c}\text { Mass } \\
\text { balance }\end{array}$ \\
\hline Acid degradation (1N HCl) & 15.5 & 84.2 & 4.169 & 10.743 & 99.7 \\
\hline Alkali degradation (1N NaOH) & 15.2 & 84.4 & 4.138 & 10.779 & 99.6 \\
\hline Peroxide degradation (30\% Peroxide) & 14.1 & 85.2 & 2.544 & 10.693 & 99.3 \\
\hline $\begin{array}{c}\text { Reduction degradation (30\% sodium bi } \\
\text { sulphate) }\end{array}$ & 13.7 & 85.4 & 2.585 & 10.671 & 99.1 \\
\hline Thermal (sample, $\left.70^{\circ} \mathrm{C}, 6 \mathrm{Hrs}\right)$ & 11.2 & 87.6 & 4.115 & 10.769 & 98.8 \\
\hline $\begin{array}{c}\text { Photo (UV-Vis light- }\left(200 \mathrm{~W} \mathrm{~h} / \mathrm{m}^{2}\right) \text { and } \\
\text { fluorescent light }(1.2 \mathrm{milliion} \text { lux-h) }\end{array}$ & 12.5 & 86.1 & 4.114 & 10.757 & 98.6 \\
\hline
\end{tabular}

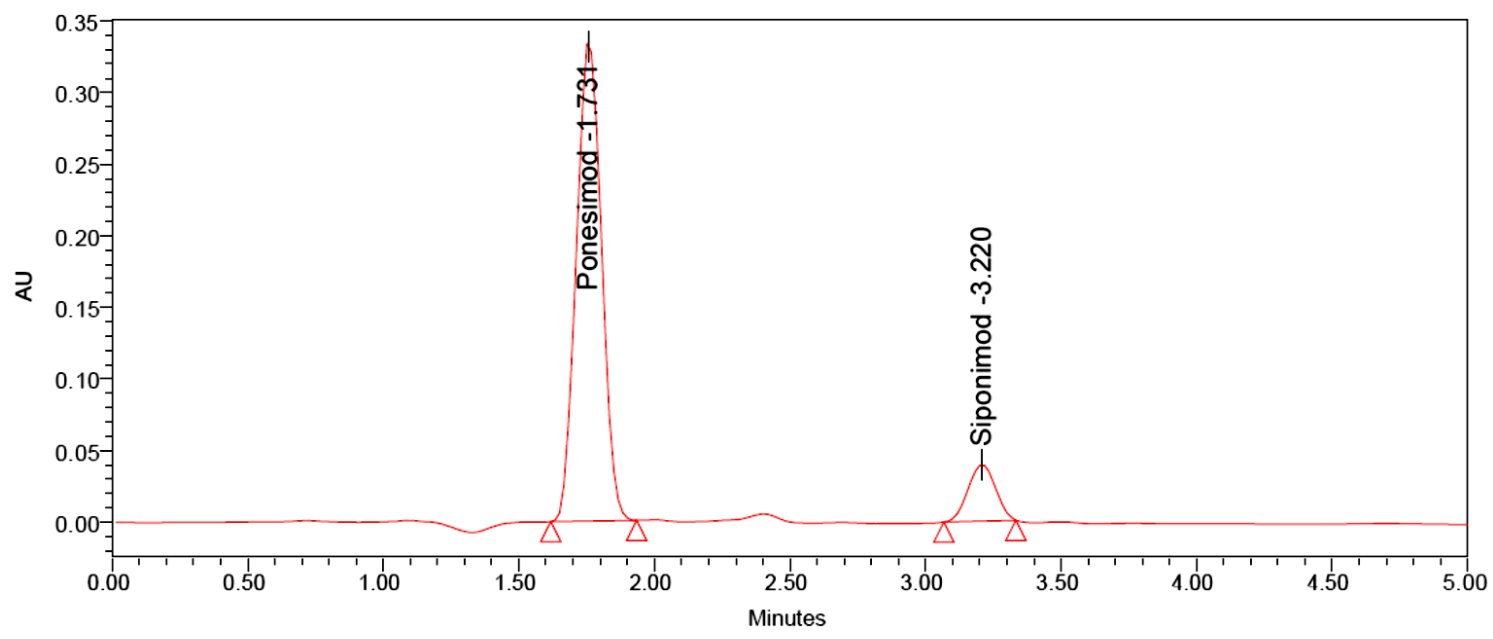

Figure 6. Chromatogram of control degradation 


\section{Conclusion}

In this study, a novel, quick, sensitive, and easy-to-use UPLC method was developed for the simultaneous estimation of Ponesimod and Siponimod in API and pharmaceutical dosage types. Because there are no UPLC or HPLC methods published, this approach is the most practical option. Shorter run time, low cost, and all the other characteristics are benefits. Identifying many Standards necessitates considering these qualities. All the parameters were verified and were found to be within the acceptable range, including linearity, accuracy, specificity, robustness, and process precision. According to our research, the RSD values for all the parameters came in at less than $2 \%$, showing that the procedure is accurate and that the results we found are consistent. Therefore, it's possible to use the current approach in QC laboratories for routine study and manufacturing Ponesimod and Siponimod pharmaceuticals without having to separate the substances first.

\section{Acknowledgement}

The authors want to thank Shree Icon Pharmaceutical Laboratories for giving them all the necessary equipment to finish their work.

\section{Conflicts of Interest}

None

\section{Funding Support}

None

\section{References}

[1] J. Nakahara, M. Maeda and S. Aiso, "Current concepts in multiple sclerosis: autoimmunity versus oligodendrogliopathy”, Clin Rev Allergy Immunol. vol. 42, no. 2, (2012), pp. 26-34.

[2] N. Tataru, C. Vidal C and P. Decavel, "Limited impact of the summer heat wave in France (2003) on hospital admissions and relapses for multiple sclerosis", Neuroepidemiology. vol 27, no. 1, (2006), pp. 28-32.

[3] Q. Hao, B. R. Dong, T. Wu, "Probiotics for preventing acute upper respiratory tract infections", Cochrane Database Syst Rev. vol. 9, no. 2, (2015), pp. CD006895.

[4] T. Weidner and T. Schurr "Effect of exercise on upper respiratory tract infection in sedentary subjects", British Journal of Sports Medicine. vol. 37, no. 4, (2013), pp.304-306.

[5] T. Giboney Paul, "Mildly Elevated Liver Transaminase Levels in the Asymptomatic Patient”, Am Fam Physician, vol. 71, no. 6, (2005), pp. 1105-1110.

[6] R. C. Oh, T. R. Hustead, "Causes, and evaluation of mildly elevated liver transaminase levels", Am Fam Physician, vol. 84, no. 9, (2011), pp. 1003-1008.

[7] N.R.Poulter, D. Prabhakaran, M.Caulfield, "Hypertension”, Lancet, vol. 386, no. 9995, (2015), pp. 801-12.

[8] Ye Fan, M. Hatahet, A. M. Youniss, “The Clinical Significance of Relative 
Bradycardia" WMJ, vol. 117, no. 2, (2018), pp. 73-78.

[9] N. Williams, "The MRC breathlessness scale”, Occup Med (Lond), vol. 67, no. 6, (2017), pp. 496-497.

[10] J. R. Shiber, J. D. Santana, Med Clin North Am, vol. 90, no. 3, (2006), pp. 45379.

[11] G. Shivaraj, B. D. Prakash, V. H. Vinayak, "A review on laboratory liver function tests", Pan Afr Med J, vol. 3, no. 17, (2009), pp. 17.

[12] Y. Kwo Paul, M. Cohen Stanley, K. Lim Joseph. "ACG Clinical Guideline: Evaluation of Abnormal Liver Chemistries", Am J Gastroenterol, vol. 112, no. 1, (2017), pp. 18-35.

[13] M. Hoch, B. Darpo, P. Brossard. "Effect of ponesimod, a selective S1P1 receptor modulator, on the QT interval in healthy individuals", Basic Clin Pharmacol Toxicol, vol. 116, no. 5, (2015), pp. 429-437.

[14] D. S. m, C. E. Heise, N. Ancellin. "Characterization of a novel sphingosine 1phosphate receptor, Edg-8”, J Biol Chem, vol. 275, no. 19, (2000), pp. 1428114286.

[15] S. Long Jaclyn, Y. Fujiwara, J. Edwards. "Sphingosine 1-Phosphate Receptor 4 Uses HER2 (ERBB2) to Regulate Extracellular Signal Regulated Kinase-1/2 in MDA-MB-453 Breast Cancer Cells", J Biol Chem, vol. 285, no. 46, (2010), pp. 35957-35966.

[16] R. Ahmed, Z. Omidian, A. Giwa. "A Public BCR Present in a Unique DualReceptor-Expressing Lymphocyte from Type 1 Diabetes Patients Encodes a Potent T Cell Autoantigen”, Cell, vol. 177, no. 6, (2019), pp. 1583-1599.

[17] A. J. Dyckman. "Modulators of Sphingosine-1-phosphate Pathway Biology: Recent Advances of Sphingosine-1-phosphate Receptor 1 (S1P1) Agonists and Future Perspectives", J Med Chem. vol. 60, no. 13, (2017), pp. 5267-5289.

[18] Y. Mao-Draayer, J. Sarazin, F. David. "The sphingosine-1-phosphate receptor: A novel therapeutic target for multiple sclerosis and other autoimmune diseases", Clin Immunol. (2017)175(Supplement C): pp. 10-15.

[19] G. S. Gronseth, M. K. Greenberg. "The utility of the electroencephalogram in the evaluation of patients presenting with headache: A review of the literature", Neurology. vol. 45, no. 7, (1995), pp. 1263-1267.

[20] X. A. Hao, C. C. Xue, L. Dong, Z. Zheng. "Factors associated with conflicting findings on acupuncture for tension-type headache: qualitative and quantitative analyses", J Altern Complement Med. Vol. 19, no. 4, (2013), pp. 285-297.

[21] J. Booth. "A short history of blood pressure measurement”, Proc R Soc Med. vol. 70, no. 11, (1977), pp. 793-799.

[22] G. Antonietta, M. Alessandra, B. Silvia. "Siponimod (BAF312) prevents synaptic neurodegeneration in experimental multiple sclerosis", Journal of Neuroinflammation. Vol. 13, no. 1, (2016), pp. 207.

[23] M. K. Raviraj, S. B. Vijaykumar, B. Santhakumari. "Mechanistic and Spectroscopic investigations of $\mathrm{Ru}^{+3}$ catalyzed oxidative degradation of Azidothymidine by heptavalent manganese at environmentally relavant $P H$ ", Desalination and Water Treatment. Vol. 57, no. 58, (2016); pp. 28349-28362. 
[24] M. K. Raviraj, S. B. Vijaykumar, B. Santhakumari. "Oxidative transformation of antiretroviral drug Zidovudine during water treatment with permanganate:

reaction kinetics and pathways", Desalination and Water Treatment. vol. 57, no. 52, (2016), 24999-25010. 